Referencia para citar este artículo: Perrupato, S. (2017). Pensar la historia de las instituciones educativas en la Argentina: aportes para el debate. Revista Latinoamericana de Ciencias Sociales, Niñez y Juventud, 15 (2), pp. $797-806$. DOI:10.11600/1692715x.1520102082016

\title{
Pensar la historia de las instituciones educativas en la Argentina: aportes para el debate*
}

\author{
SEBASTIÁN PERRUPATo** \\ Profesor Universidad Nacional de Mar del Plata, Argentina.
}

\begin{abstract}
Artículo recibido en agosto 2 de 2016; artículo aceptado en febrero 28 de 2017 (Eds.)
\end{abstract}
- Resumen (descriptivo): la historia de las instituciones educativas en la Argentina ha sido tradicionalmente asociada a paradigmas manidos de investigación histórico-educativa. Recién en las últimas décadas comienzan a resurgir estudios que entienden la necesidad de realizar análisis institucionales que entrecrucen lo educativo y lo histórico. En este sentido, se hace necesario un replanteo serio sobre los métodos y las formas de hacer y de pensar esta historia que trascienda los lineamientos de la tradición positivista.

El presente trabajo tiene por fin analizar los aportes que se hacen al campo de la Historia social de la educación a partir de tres direcciones. Desde los estudios psicosociales de las instituciones educativas; desde las teorías del poder con la propuesta de Michael Foucault y desde la sociología institucional de Pierre Bourdieu. Entendemos que el cruce entre estas perspectivas le otorga a los y las docentes e investigadores un marco metodológico por demás dinámico para comprender la historia educativa desde una perspectiva institucional.

Pensar la historia de las instituciones educativas desde esta perspectiva multidimensional se transforma no solo en un método de investigación histórico educativo, sino también en la forma en que los docentes y las docentes pueden reflexionar sobre sus propias prácticas en las instituciones de enseñanza.

Palabras clave: historia de la educación, instituciones de enseñanza, sociología de la educación, psicosociología educativa (Tesauro de Ciencias Sociales de la Unesco).

\section{Thought related to the history of educational institutions in Argentina: contributions to the debate}

- Abstract (descriptive): the history of educational institutions in Argentina has traditionally been associated with hackneyed historical paradigms of educational research. Only in recent decades have studies begun to surface that understand the need for institutional analysis that combines the educational and the historical. In this sense, there is a need to seriously reconsider the methods and ways of thinking about this history so that this work transcends the influence of the positivist tradition.

This paper aims to analyze the contributions made to the field of Social History of Education from three areas: psychosocial studies of educational institutions; the theories of power developed

Este artículo de revisión de tema sobre Historia de la educación forma parte de las investigaciones desarrolladas en el marco del Doctorado en educación de la Facultad de Humanidades y Artes de la Universidad Nacional de Rosario. El título de la investigación es La vida en las aulas universitarias de la Colonia. Un análisis del curriculum y las prácticas de enseñanza en la Universidad de Córdoba a través de la dialéctica tradición- modernización. El Proyecto de investigación se encuentra aprobado con fecha de Mayo de 2015 y se estipula finalización para diciembre de 2017. Resolución 333/15 del Consejo Directivo de la Facultad de Humanidades y Artes de la Universidad Nacional de Rosario. Gran área de conocimiento: Ciencias Sociales; subárea: Ciencias de la Educación.

** Profesor y licenciado en Historia. Especialista en educación (Facultad Latinoamericana de Ciencias Sociales) y en Docencia Universitaria (UNMdP). Máster en historia del mundo atlántico (Universidad Jaume I, España). Doctor en Historia (UNMdP). Doctorando en educación (UNR) Profesor Facultad de Humanidades, Universidad Nacional de Mar del Plata. Orcid: 0000-0002-4228-9573. Índice H5: 2. Correo electrónico: sperrupato@gmail.com 
by Michael Foucault; and the institutional sociology of Pierre Bourdieu. The author proposes that the intersections of these perspectives give teachers and researchers a methodological framework to understand educational history from an institutional perspective.

To contemplate the history of educational institutions using this multidimensional perspective is not just a method of educational historical research but also a way in which teachers can reflect on their own practices in educational institutions.

Key words: history of education, educational institutions, sociology of education, educational psychosociology (Unesco Social Sciences Thesaurus).

\section{Pensar a história das instituições educativas na Argentina, aportes para o debate}

- Resumo (descritivo): A história das instituições de ensino na Argentina tem sido tradicionalmente associada com paradigmas históricos banais de pesquisa educacional. Apenas nas últimas décadas começam a ressurgir estudos que entendem a necessidade de análise institucional que cruzam o educativo e a história. Neste sentido, um sério repensar sobre os métodos e modos de fazer e pensar nesta história que transcende as diretrizes da tradição positivista é necessário.

Este trabalho tem como objetivo analisar as contribuições para o campo da História Social da educação a partir de três direções: desde os estudos psicossociais de instituições de ensino; a partir das teorias de poder com a proposta de Michael Foucault e da sociologia institucional de Pierre Bourdieu. Entendemos que a intersecção dessas perspectivas oferece aos professores e investigadores um quadro metodológico mais que dinâmico para compreender a história da educação do ponto de vista institucional.

Pensar a história das instituições educacionais a partir dessa perspectiva multidimensional torna-se não só um método de pesquisa histórica de ensino, mas também na maneira que permite aos professores refletir sobre suas próprias práticas em instituições de ensino.

Palavras-chave: história da Educação, instituições de ensino, sociologia da educação, psicologia da educação (Thesaurus de Ciências Sociais da Unesco).

-1. Introducción. -2. Repensando la historia de la educación. -3. El análisis de lo institucional. -4. Y por qué no las relaciones de poder. -5. Consideraciones finales. -Lista de referencias.

\section{Introducción}

Habitualmente los/las docentes transitamos por espacios, lugares e instituciones que se nos van haciendo cotidianos, sin detenernos a pensar sobre los orígenes de los mismos. Es así como una y otra vez repetimos actos, prácticas o discursos sin saber cuál es el verdadero sentido de lo que hacemos o decimos. Hace algunos años Michel Foucault (2014a) le hacía una pregunta a los psiquiatras y personal penitenciario: ¿Son capaces de soportar su propia historia? (p. 161). Creo que la misma pregunta vale hoy para los/las docentes: ¿Somos capaces de soportar nuestra propia historia?

Pensar la historia de las instituciones educativas significa repensarnos a nosotros mismos como agentes institucionales comprendiendo el verdadero alcance de aquello que realizamos. En este sentido, resulta fundamental la articulación de una historia institucional que abandone los viejos lineamientos de la historia positiva y se transforme en una práctica social y cultural que tienda a repensarnos como actores sociales de la institución. Repensando nuestras propias prácticas que, como mencionaba Jorge Huergo (2015), "Cargan con tradiciones enmudecidas que hablan de gestos, posiciones, quehaceres, pensamientos, hábitos, relaciones" (p. 15) muchas veces difíciles de evidenciar y que impiden la tarea de transformarlas.

El presente trabajo pretende analizar y discutir el lugar de la historia de las instituciones educativas en la actualidad. Pretendemos un cruce entre la perspectiva historiográfica y el campo de las instituciones educativas. Esta última nos abre una nueva oportunidad de 
análisis al entender que en las instituciones se articulan una serie de prácticas, redes y relaciones de poder que no fueron comprendidas desde la perspectiva de la historia tradicional.

Como ha afirmado Lidia Fernández, la relación de la escuela con el medio es uno de los aspectos más destacados como "deber ser" pedagógico, la escuela cumple un mandato social general, asociado con su génesis. Por un lado, la ubicación en el espacio muestra el grado de conexión o retraimiento de la institución y su medio inmediato respecto de los centros en los que se concentra el poder social e institucional. Por otro, la ubicación socio histórica permite conocer los fines sociales y los objetivos que se espera cumplir al tiempo que permite comprender las características del "mandato social" que pesa sobre la institución redefiniendo su cultura (Fernández, 1998, p. 82).

\section{Repensando la historia de la educación}

Se ha discutido mucho (y aún hoy es tema de interés) el lugar que corresponde a la Historia de la Educación como campo especifico. Tradicionalmente esta ha recibido un lugar residual en los libros de formación y fue supeditada a la historia de las corrientes filosóficas, de la cultura o de la civilización debido al escaso lugar que recibía en los ámbitos de investigación y generación de conocimiento.

La necesidad de esta historia para la formación de docentes llevó a numerosos pedagogos a ocuparse de ella. Surgía así recortada no a partir de un interés genuino de los "historiadores profesionales", sino en vistas de la necesidad de los "pedagogos" de legitimar sus propias prácticas (Cucuzza, 1996). Esto condujo a un recorte del objeto de estudio y al corrimiento del interés hacia las ideas pedagógicas, las instituciones educativas y las políticas escolares, que pretendían mostrar la escuela como único modo de transmisión de saberes. Esta tradición no se mantuvo alejada del positivismo dominante sobre el que se construyó, siendo exclusiva del mismo hasta entrada la década del ochenta del siglo XX.
Desde la perspectiva institucional la historia se focalizó en la riqueza de los documentos que existían en las instituciones, presentándolas fuera de cualquier contexto socio histórico cultural, pero enfatizando los procesos políticos. En este sentido, la historia de las instituciones educativas se planteó como una suerte de relato cronológico de las etapas por las atravesaba la institución, perdiendo de vista las prácticas educativas, los actores, las relaciones de poder, el contexto entre otros elementos que permiten comprender la institución de un modo integro. En la Argentina los nombres de los historiadores de esta línea son por todos conocidos: BustosFerreyra (1901), Garro (1882), Probst (1924), Martínez-Paz (1940), entre otros.

La renovación historiográfica que encarnó la fundación de Annales, hacia fines de la década del veinte, planteaba el fin del positivismo dominante. Así la historia dejaba de ser la narración "verídica" y cronológica de los acontecimientos pasados para convertirse en "La forma intelectual en la que una civilización da cuenta a sí misma de su pasado” (Huizinga, 1968, p. 37). Entonces comenzaba a aceptarse la imposibilidad de una objetividad absoluta y a utilizarse nuevos métodos y fuentes.

En la segunda mitad del siglo XX cambió la dirección de Annales y los nuevos directores ahondaron aún más en la incorporación de nuevas fuentes y la interdisciplinariedad de las ciencias. De este modo, la psicohistoria y la historia social dejaban paso a una historia geográfica y económica que, sin abandonar la pretensión de totalidad, profundizaba en la larga duración.

El nacimiento de la revista Past and Present en 1952 abrió a la historiografía una nueva forma de analizar los acontecimientos. Influenciada por la escuela de los Annales y el marxismo, hacía especial hincapié en las experiencias, acciones y luchas históricas de las clases bajas. Lo que posteriormente se denominó Historia desde abajo.

Sin embargo, podemos afirmar que la renovación historiográfica no llegaría al campo de la educación hasta la década del ochenta. Con ella y la propuesta de "abrir la historia" se comenzaba a mirar hacia otros objetos de estudio que hasta ese momento habían sido desconocidos para la historia. 
En este contexto surgió la Historia Social de la Educación. Caracterizada por su impronta pedagógica, entendía la educación como un elemento constitutivo de lo social, como un hecho social de importancia para la comprensión de la realidad. Como afirmó Nava-Rodríguez (2004), "Más allá de la evidente historicidad del hecho educativo, su dimensión sociocultural solo empieza a adquirir carta de naturaleza en fechas reciente" (p. 10).

No se trata de circunscribir el tratamiento a discusiones pedagógicas pretéritas o a las manifestaciones más evidentes de la praxis formadora, sino de entender la educación como una función especial y fundamental de la cultura (Esteban-Mateo, 1983), como un producto de época y un agente activo de transformación social (Viñao-Frago, 2000).

Contrario a esto, buena parte de la historia de la educación ha sido enfatizando en los procesos sin tener en cuenta los sujetos, olvidando el carácter social de los mismos y sus relaciones de poder. Como ha afirmado Julia Varela (2003) se trata de entender la construcción de la verdad histórica, la naturaleza y las funciones de la educación, así como su relativa autonomía en la producción de los discursos, estrategias, prácticas y esferas poder.

Adrian Ascolani (1998) ha señalado que la historiografía educacional argentina atraviesa por un momento de intensa producción, de superación cualitativa en lo analítico y de diversificación de su objeto de estudio. La estabilidad político- institucional de los últimos quince años ha contribuido a este desarrollo pero al mismo tiempo ha generado cierta disparidad en el desarrollo entre las diferentes regiones de América Latina (Arata \& Southwell, 2014). La mayoría de los planes de estudios de los profesorados a nivel nacional incluyen dentro de sus disciplinas historia de la educación. En casi todos con una perspectiva social. Las historias institucionales recién se han desarrollado más en los últimos años de la mano de historiadores nobeles que hacen de este ámbito su objeto de estudio.

"La historia de la educación (...) deconstruye, desmitifica y empala las grandes heroicas y a menudo exageradas historias del discurso educativo de acuerdo con la fe modernista en el progreso, no para ridiculizar a nuestros predecesores, su educación o sus ideales, sino para demostrar que también ellos fueron simples humanos que vivieron en un contexto socio histórico concreto del que difícilmente podían abstraerse" (Depaepe, 2009, p. 10).

Los riesgos del presentismo ampliamente denunciados por los historiadores tradicionales se encuentras ya caducos. Todos coinciden en que es una condición inevitable de la investigación histórica. Como ha señalado Foucault, estamos históricamente condenados a la historia, a la paciente construcción de discursos sobre discursos de prácticas sobre prácticas.

\section{El análisis de lo institucional}

Los análisis institucionales han aumentado mucho en los últimos años de la mano de la perspectiva psicoanalítica y los aportes del marxismo y las teorías del conflicto. La institución educativa se entendió así como un campo de análisis psicosocial en el cual, la educación era reflejo de los conflictos institucionales que se generaban.

Desde las teorías sociológicas clásicas la institución se ha concebido como un significativo espacio de análisis sobre la realidad social. De este modo la institución no podría desligarse de su impronta socio histórica, no solo por ser parte de la sociedad si no por ser también un organismo de socialización de los sujetos.

Por su parte, para los análisis institucionales más tradicionales, la institución se convirtió en análoga de establecimiento (organización con una función especializada, un espacio propio y un conjunto de personas) y el establecimiento se convierte también en "un objeto de relación, es portador de significados y funciona en el campo psicológico como un sector de importancia, variante según el sujeto y sus circunstancias con el que se establece un vínculo" (Fernández, 1998, p. 21). Así, la institución supone conflictos en los cuales se integran lógicas y ordenes de realidad diferentes que forman una estructura institucional heterogénea. 
En la Argentina el crecimiento de esta corriente se dio de la mano de Lidia Fernández que ha volcado todo el desarrollo de la psicología social al análisis de las instituciones primero de salud y después educativas. Sin embargo, temas como la organización formal e informal, los sistemas de liderazgo, la autoridad o los conflictos, han "acaparado" la atención de los investigadores relegando o ignorando el conocimiento de la historia institucional que es una pieza clave en el análisis de los establecimientos educativos.

La organización es definida Aldo Schlemenson (1993) como un sistema social y técnico que incluye e integra seis dimensiones: el proyecto institucional; la estructura; la integración psicosocial; las condiciones de trabajo y el contexto. El contexto se transforma así en un elemento constitutivo de la institución. En este esquema es que Lidia Fernández (1998) incluye las perspectivas ubicación, espacio y tiempo. Sin embargo, esta perspectiva ha descuidado frecuentemente este último punto tendiendo a comprender la institución y la vida institucional como una planta que crece, se desarrolla y muere, en el caso de las instituciones educativas con crisis periódicas.

Esta visión no concibe entonces a la institución de un modo histórico, según el cual se debería comprender la importancia de los actores sociales, como verdaderos agentes de cambio, sino desde una perspectiva biologicista o clínica, en la cual las instituciones pasan por situaciones similares, a las que es factible en caso de problema o enfermedad aplicar una cura.

Lo antedicho no implica negar la importancia que esta corriente ha tenido y tiene para el desarrollo de una historia institucional, por el contrario, se trata de comprender sus limitaciones para, a partir de allí utilizar algunas herramientas que sirvan al análisis socio histórico de la institución.

\section{Y por qué no las relaciones de poder}

La perspectiva antes descripta proveniente de la psicología social ha nutrido los estudios sobre el campo de las instituciones educativas en la Argentina desde el regreso de la democracia.
Sus planteos han relegado la posibilidad de analizar las instituciones también como nodos de poder microfísico, negando la posibilidad de comprender las prácticas y los discursos institucionales dentro de una lógica que excede lo institucional, interrelacionándose con otras instituciones y actores sociales que muchas veces tienen un peso más que significativo en la constitución de la institución.

Desde esta óptica dos perspectivas debieran de complementar la historia de las instituciones educativas: La filosófica y la sociológica. Foucault y Bourdieu han trabajado desde estas líneas encontrando en las instituciones su punto de contacto, su lugar común. El filósofo reivindicó la perspectiva historicista desde su análisis institucional de la prisión y el neuro-psiquiátrico. Por su parte, el sociólogo ayudó a comprender la institución en un contexto más amplio, como resultado de flujos de interrelación continua con la sociedad, la cultura y su historia.

Innumerables son las obras de Michael Foucault, sin embargo entre ellas no encontramos ninguna que haya dedicado exclusivamente a la educación. En escritos como Vigilar y castigar, el autor, esboza algunas líneas sobre el tema, sobre todo en torno a la disciplina, sin consagrase al tema. Su preocupación por comprender la dinámica interna de las instituciones lo llevó a entender la educación como una instancia de control social. La propuesta de Foucault buscaba analizar el poder de la norma por medio de diferentes dispositivos como los hospitales, los manicomios, las cárceles y las escuelas entre otros (Caimari, 2004, p. 19).

Para el filósofo desde finales de la centuria ilustrada se superponen dos tipos de tecnologías de poder: las disciplinarias y las reguladoras de la vida. Ambas se articulan optimizando la vida individual y social, y por lógica institucional. Al mismo tiempo comienzan a circular nuevas técnicas de racionalización, tecnologías de un poder microfísico, lo que implica la formación de nuevas formas de saber y sus respectivas instituciones. Estas nuevas formas de saber tienen un doble objetivo en primer lugar jerarquizar, clasificar, vigilar y adiestrar los cuerpos, y en segundo gestionar de modo global la vida (Varela, 1993, p. XI). 
En este contexto, las tecnologías y saberes disciplinarios así como la manifestación de un poder opresivo -que Foucault denomina relaciones de dominación- constituyen la subjetividad. Esa tecnología disciplinaria hace del panóptico dispositivo por excelencia para dirigir las conductas. Junto con éste, la reglamentación del tiempo, la diagramación del espacio, la división de los individuos, y los mecanismos de seguridad colectiva completan el cuadro de dispositivos de dominación y control social (Valladeres-Portillo, 2010).

A partir de las relaciones entre el poder y el saber lo que algunos autores han llamado metodología foucaultiana ${ }^{1}$ enfrentó las pretensiones de objetividad propias del positivismo y el idealismo de las teorías puras marxistas o no marxistas. Así, los discursos del modelo genealógico se presentan de modo "heterogéneo, dispersos e inestables frente a la continuidad de la historia y a la concepción binaria del discurso dominante-discurso dominado" (Galván, 2011).

Como ha afirmado Julia Varela:

"La aplicación del modelo genealógico a las instituciones educativas permite la realización de una serie de análisis que pone de manifiesto los conflictos, antagonismos y contradicciones del campo educativo, descubre la ambigüedad fundamental de las prácticas escolares, revela las razones ocultas de su existencia y permite comprender las imbricaciones específicas de los saberes y poderes que la constituyen" (Varela, 1979, p. 20).

Los aportes de Foucault en torno a las teorías del poder nos brindan solidas herramientas para la interpretación de los discursos educativos en los que subyacen normalización y resistencias de las propias instituciones. Evidentemente no se puede, a partir los escritos del filósofo, crear un modelo de análisis que permita comprender

1 Algunos filósofos, sociólogos, historiadores e incluso cientistas educacionales, pretendieron ver en la obra de Foucault una metodología de análisis que trascendía y superaba a las del marxismo y al funcional estructuralismo. Sin embargo, como él mismo ha señalado, no existe una metodología foucaultiana aunque sí elementos, y herramientas de análisis que Foucault utiliza y que retoma de otras metodologías que nos ayudan a comprender y delinear nuestro propio objeto de análisis, en este caso la escuela (Foucault, 2014b). las formas de socialización, ni escolares ni de otra institución cualquiera sea. No obstante sí se puede, entendiendo el conjunto de procesos que operan en las instituciones, utilizar estas teorías para la comprensión de las formas de subjetividad que se gestan y que implican también la formación de nuevos saberes $\mathrm{y}$ poderes (Varela, 1993, p. XII).

Recientemente las producciones historiográficas parecieran haber descubierto que las instituciones están formadas por sujetos susceptibles de análisis. Esto posibilita redescubrir que los sujetos se relacionan con los "dispositivos" de diversas formas que trascienden la linealidad pretendida por la historiografía tradicional (Bohoslavsky, 2005). No se trata de considerar a las instituciones de manera objetiva, esperando a quién quiera hacer uso de ellas, sino que invitan a considerar a los sujetos como actores sociales con capacidad cognitiva y reactiva. En este sentido, son capaces de interpretar el contexto en el que están inmersos y actuar sobre él a fin de orientar la situación en un sentido favorable a sí mismos.

Los sujetos pasan de ser descriptos como meras víctimas de los "dispositivos" a ser interpretados como "sujetos capaces de apropiarse de manera selectiva e instrumental de aspectos que le resultaban beneficiosos de las instituciones de control. Son sujetos que se transformaban en negociadores activos de su presente, atendiendo a sus condiciones históricas reales" (Caimari, 2004, p. 23). Esto no implica dejar de comprender que por momentos se vuelvan víctimas de procesos que no eligieron, pero sí que no se trata de arcilla que espera dócilmente la llegada de agentes más poderosos para que los moldeen de acuerdo a sus necesidades.

Consideración simultánea merece la propuesta de Bourdieu que entiende la institución escuela dentro del complejo entramado social y como corolario tendiente a la reproducción social de las clases privilegiadas. Este sociólogo francés nos aporta un conjunto de estrategias tendientes a reproducir el orden social vigente que se transforman en modos de dominación, para este autor, la sociedad reposa sobre dos principios dinámicos en relación, de variada importancia de acuerdo a las sociedades 
estos se inscriben en las estructuras objetivas de distribución de capital y en la reproducción social (Bourdieu, 2011, p. 32).

Las distintas estrategias de reproducción para el autor, son: estrategias de inversión biológica, sucesoria, educativa, de inversión económica y de inversión simbólica. De todas, la que más nos interesa debido a nuestro objeto de estudio es la tercera en la que no se hace hincapié en el aspecto económico, como creyó la Teoría del Capital Humano ${ }^{2}$, sino que se pone especial énfasis en el aspecto cultural. Debemos entender que estas estrategias no tienen una intención consciente ni racional. Por el contrario se trata de disposiciones del habitus $^{3}$ que tienden espontáneamente a la reproducción.

Este esquema se entiende si se comprenden los diferentes tipos de capitales de los cuales el capital cultural puede permanecer en estado objetivado, es decir en formas de objetos y soportes materiales o incorporado, definido como "un tener devenido en ser, una propiedad hecha cuerpo, una parte integrante de la persona, un habitus" (Bourdieu, 2011, p. 215).

Desde siempre la sociedad se ha regulado por diversos mecanismos que se utilizan para imponer determinado orden social; estos mecanismos, así como las instituciones que los acompañan corresponden al concepto de control social. De aquí se desprenden algunas diferencias entre Foucault y Bourdieu que es preciso mencionar. Para el primero el sujeto es el que construye el poder, poniendo en evidencia la violencia que su ejercicio conlleva, así como también las condiciones de posibilidad del mismo sujeto. Para el segundo, en cambio, el

2 La teoría del capital humano tiene sus cimientos en la economía, particularmente en dos autores: Theodor Schultz y Gary Becker. Ellos planteaban que la educación se asimilaba con el beneficio de cualquier capital material, por lo tanto se trataba de una inversión factible de rentabilidad (Becker, 1983; Schultz, 1983).

3 El concepto de habitus de Bourdieu ha sido bastante debatido en el ámbito académico. Se ha intentado incluso asimilarlo al concepto tradicional de cultura, también se puede mantener más cercano a su concepción original en tanto parte de la sociedad. Así, él mismo lo definiría como "un sistema de disposiciones duraderas y trasladables, estructuras estructuradas dispuestas a funcionar como estructuras estructurantes, es decir, en cuento principios generadores y organizadores de prácticas y representaciones que pueden ser objetivamente adaptadas a su meta sin suponer la orientación consciente a fines y el control expreso de las operaciones necesarias para alcanzarlos" (1991, p. 88). sujeto se encuentra inmerso en una estructura que lo contiene y lo define (Mateo \& Antoniucci, 2013).

Desde la perspectiva foulcaultiana el poder necesita legitimarse y es en esta legitimación donde radican los fundamentos de la dominación. Así, es precisamente en los dispositivos disciplinarios que -tienden a generar cuerpos dóciles y útiles- en donde radica el poder.

En los análisis de Bourdieu las luchas por el poder se dan al interior de la estructura misma y casi siempre a partir de sus relaciones simbólicas. En ellas el capital (cultural y económico) es constituyente del espacio social, pero también es producto de las relaciones entre agentes e instituciones.

$\mathrm{Si}$ entendemos que la dominación es una forma de dar cuenta del poder, debemos comprender la diferencia que existe en este concepto para ambos autores. El sociólogo francés prefiere comprender poder y dominación como partes esenciales de la cultura donde la lucha por la apropiación del capital simbólico reproduce las diferencias sociales. Lo cual se transforma en una lucha por imponer su forma de ver el mundo cultural, política y económicamente. En palabras de Bourdieu (2011):

"El dominante es quien llega a imponer su propia percepción, a ser percibido como él se percibe, a apropiarse su propia objetivación, reduciendo su verdad objetiva a su intención subjetiva" (p. 192).

Por ello la dominación evita la violencia física solo en la medida en que está legitimada por las instituciones, es decir, por medio de la legitimación la violencia física se transforma en violencia simbólica. Para Foucault, en cambio, las instituciones coaccionan a los individuos a través de la violencia. Ambas tendencias tienen aquí un punto de contacto: "Bourdieu observa en la institucionalización algo parecido a la tecnología disciplinaria y panóptica de Foucault, pues el valor social se disloca, la autoridad se transporta hacia otro lugar que no es "uno" sino "algo": la institución" (Moreno, 2006, p. 5). 
Desde esta perspectiva, entendemos que ambas teorías pueden resultar complementarias ya que buscan esos ejercicios de poder que parecen ocultos. $\mathrm{Y}$ analizan la resistencia que genera dicho poder. La trama capilar y la estructura tienen su punto de contacto en las instituciones, donde el poder se presenta por momentos dinámico $\mathrm{y}$, por momentos estructurado, pero siempre ejercido desde los sujetos.

\section{Consideraciones finales}

Pensar la historia de las instituciones que transitamos es repensarnos a nosotros mismos como actores sociales, es redescubrirnos como parte integrante de una sociedad, cuyas relaciones muchas veces nos exceden. Por ello entendemos necesario que los/las docentes pensemos nuestras historias institucionales, nuestras biografías institucionales, para comprender el lugar desde el cual estamos construyendo la enseñanza.

Es en este sentidoquelahistoriainstitucional no toma la vieja impronta positivista en la cual las instituciones se analizaban como objetos ajenos a nuestra realidad de investigadores, de docentes y de personas. La riquezas de los documentos institucionales llevó a explotar esta perspectiva, sin embargo, más allá de lo documental, la institución encierra un corpus de información (otras voces), tanto o más valioso y que permite comprender, entender y analizar de manera más acabada los verdaderos sentidos de la historia educativa.

Entender la educación en este marco implica comprenderla como un elemento de control social y al mismo tiempo de reproducción. En este sentido, la educación encuentra el fundamento de su práctica en la comprensión de un universo más amplio que incluye distintos ejes: la articulación del contenido, el docente y el alumno pero también el contexto histórico, la relación teoría-práctica, la relación poder-saber y la vida cotidiana (Guyot, Fiezzi, \& Vitarelli, 1995).

La memoria que se guarda en los actores, los objetos, los espacios y las prácticas es, muchas veces, más valiosas que la documentación oficial que la institución guarda en sus archivos o bibliotecas. Y ellas siguen ahí aguardando a que un investigador ávido de conocimiento, o los/las propios/as docentes preocupados por pensar sus orígenes, se animen a bucear en esas aguas.

Los/las docentes debemos convertirnos en actores institucionales plenos capaces de conocer y construir nuestra propia historia, es así que conociéndola podemos intervenir en ella. El análisis historiográfico sumado a los aportes de la sociología otorgan ya una visión renovada a la forma tradicional de hacer historia. Sin embargo, los aportes del campo de las instituciones educativas abre una nueva oportunidad de análisis al entender que en las instituciones se articulan prácticas, redes y relaciones de poder que son propias de los dinamismos internos de la las instituciones y dan cuenta de su complejidad.

En cualquier caso, no existe un método perfecto para la historia de las instituciones educativas, pero ampliar la mirada, cruzando los aportes de la sociológica y de la psicología social o institucional permite a los/las docentes comprender mejor su propia historia comprendiendo a la escuela como una institución con una vida, un contexto y una multiplicidad de actores que están ahí, dispuestos a contar su historia.

\section{Lista de referencias}

Arata, N. \& Southwell, M. (2014). Ideas de la educación latinoamericana. Un balance historiográfico. Buenos Aires: Unipe.

Ascolani, A. (1998). Historiadores e Historia educacional Argentina. Una mirada retrospectiva de su estado actual. Sarmiento, 2, pp. 217-226.

Becker, G. (1983). El Capital Humano. Madrid: Alianza.

Bohoslavsky, E. (2005). Uso (y abuso) de Foucault para mirar a las instituciones de castigo en Argentina, 1890-1930. Cyber Humanitatis, 35. Recuperado de: http:// web.uchile.cl/vignette/cyberhumanitatis/ CDA/texto_sub_simple2/0,1257,PRID\%2 53D16159\%2526SCID \%253D16174\%25 26ISID\%253D576,00.html\#. 
Bourdieu, P. (1991). El sentido práctico. Madrid: Taurus.

Bourdieu, P. (2011). Las estrategias de reproducción social. Buenos Aires: Siglo XXI.

Bustos-Ferreyra, Z. (1901). Anales de la Universidad Nacional de Córdoba. Córdoba: Imprenta y Casa Editora de F. Domenici.

Caimari, L. (2004). Apenas un delincuente. Crimen, castigo y cultura en la Argentina, 1880-1955. Buenos Aires: Siglo XXI.

Cucuzza, H. (1996). Historia de la Educación en debate. Buenos Aires: Miño y Dávila.

Depaepe, M. (2009). Vieja y nueva historia de la educación. Barcelona: Octaedro.

Esteban-Mateo, L. (1983). Presente, pasado y futuro de la Historia de la Educación. II Coloquio de Historia de la educación, Valencia, España.

Fernández, L. (1998). El análisis de lo institucional en la escuela. Buenos Aires: Paidós.

Foucault, M. (2014a). El intelectual y los poderes (entrevista con Christian Panier y Pierre Watte, 1981). En M. Foucault (ed.) El poder, una bestia magnifica, (pp. 159168). Buenos Aires: Siglo XXI.

Foucault, M. (2014b). Poder y Saber (entrevista con Shigehiko Hasumi, París, 1977). En M. Foucault (ed.) El poder una bestia magnifica, (pp. 67-86). Buenos Aires: Siglo XXI.

Galván, V. (2011). La influencia de Michel Foucault en el ámbito educativo español. Revista Cuaderno de Materiales, 23, pp. 357-364.

Recuperado de: http://www.filosofia.net/ materiales/articulos/a 48.html.

Garro, J. (1882). Bosquejo histórico de la Universidad de Córdoba. Buenos Aires: Biedma.

Guyot, V., Fiezzi, N. \& Vitarelli, M. (1995). La práctica docente y la realidad. Un enfoque epistemológico. Revista Enfoques Pedagógicos, 3 (2), pp. 33-45.

Huergo, J. (2015). La educación y la vida. La Plata: Universidad de La Plata

Huizinga, J. H. (1968). Dutch Civilization in the Seventeen Century and Other Essays. Londres: Collins.
Martínez-Paz, E. (1940). El plan de estudios del deán Funes. En G. Martínez-Zuviria (dir.) Catálogo de manuscritos. Buenos Aires: Biblioteca Nacional.

Mateo, N. \& Antoniucci, M. (2013). Una perspectiva del poder en Foucault $y$ Bourdieu. Buenos Aires: Instituto Gino Germani.

Moreno, H. (2006). Bourdieu, Foulcault y el poder. Iberoforum, Revista de Ciencias Sociales de la Universidad Iberoamericana, 1 (II), pp. 1-14.

Nava-Rodríguez, T. (2004). La educación del pasado en la historiografía modernista actual. Cuadernos de Historia Moderna. Anejos, III, pp. 9-21.

Probst, J. (1924). La educación en la República Argentina durante la época colonial 1771-1810. Documentos para la Historia Argentina. Buenos Aires: Peuser.

Schlemenson, A. (1993). Análisis Organizacional y Empresa Unipersonal. Crisis y Conflictos en contextos turbulentos. Buenos Aires: Paidós.

Schultz, T. W. (1983). La Inversión en Capital Humano. Educación y Sociedad, 8 (3), pp. 26-85.

Valladeres-Portillo, E. (2010). "Foucault y la educación, una mirada desde vigilar $y$ castigar". San Miguel: Colectivo Pensamiento Jurídico Crítico. Recuperado de: http://colectivopensamientojurdicocrtico.blogspot.com.ar/2010/11/foucaulty-la-educacion-una-mirada.html

Varela, J. (1979). Aproximación al análisis genealógico de la escuela en el marco de la sociología francesa de la educación. Cuadernos de Realidades Sociales, 14-15, pp. 7-33.

Varela, J. (1993). Prólogo a la edición española. En S. Ball (ed.) Foucault y la educación, (pp. IX-XV). Madrid: Morata.

Varela, J. (2003). Conocimiento, poder y subjetivación en las instituciones educativas. Sobre las potencialidades del método genealógico en el análisis de la educación formal e informal. En T. Popkewitz, B. Franklin \& M. Pereyra, (comps.) Historia cultural y educación. Ensayos críticos sobre conocimiento $y$ 
escolarización, (pp. 127-145). BarcelonaMéxico, D. F.: Ediciones Paulinas, Pomares.

Viñao-Frago, A. (2000). Historia de l' educació como disciplina académica i camp d'investigació. Temps d'Educació, 24, pp. 79-99. 